\title{
Improved Peptidyl Linkers for Self-Assembly of Semiconductor Quantum Dot Bioconjugates
}

\author{
Lorenzo Berti, ${ }^{1,2}$, Paola Serena D'Agostino ${ }^{1}$, Kelly Boeneman ${ }^{3}$, and Igor L. Medintz ${ }^{3}(\varangle)$ \\ ${ }^{1}$ CNR-INFM, National Research Center on nanoStructures and bioSystems at Surfaces (S3), Via Campi, 213/A 41100 Modena, Italy \\ ${ }^{2}$ University of California Davis Medical Center, Sacramento, CA 95817, USA \\ ${ }^{3}$ Center for Bio/Molecular Science and Engineering Code 6900, U.S. Naval Research Laboratory, Washington, DC 20375, USA
}

Received: 28 October 2008 / Revised: 2 December 2008 / Accepted: 2 December 2008

CTsinghua University Press and Springer-Verlag 2009. This article is published with open access at Springerlink.com

\begin{abstract}
We demonstrate improved peptide linkers which allow both conjugation to biomolecules such as DNA and self-assembly with luminescent semiconductor quantum dots. A hexahistidine peptidyl sequence was generated by standard solid phase peptide synthesis and modified with the succinimidyl ester of iodoacetamide to yield a thiol-reactive iodoacetyl polyhistidine linker. The reactive peptide was conjugated to dye-labeled thiolated DNA which was utilized as a model target biomolecule. Agarose gel electrophoresis and fluorescence resonance energy transfer analysis confirmed that the linker allowed the DNA to self-assemble with quantum dots via metal-affinity driven coordination. In contrast to previous peptidyl linkers that were based on disulfide exchange and were thus labile to reduction, the reactive haloacetyl chemistry demonstrated here results in a more stable thioether bond linking the DNA to the peptide which can withstand strongly reducing environments such as the intracellular cytoplasm. As thiol groups occur naturally in proteins, can be engineered into cloned proteins, inserted into nascent peptides or added to DNA during synthesis, the chemistry demonstrated here can provide a simple method for self-assembling a variety of stable quantum dot bioconjugates.
\end{abstract}

\section{KEYWORDS}

Semiconductor quantum dot, peptide, DNA, nanocrystal, bioconjugation, iodoacetyl, sulfhydryl, polyhistidine, metal-affinity, fluorescence, fluorescence resonance energy transfer (FRET)

\section{Introduction}

Integrating nanoparticles with biological molecules to create functional nanodevices and sensors continues to be a major focus of nanotechnology research [1-4]. Among the many different nanoparticle materials being investigated, luminescent semiconductor nanocrystals or quantum dots (QDs) continue to generate growing interest due to their unique size-dependent optical and electronic properties. Projected applications include multicolor fluorescent probes and imaging/contrast agents for myriad diagnostic and research uses, hybrid organic-inorganic energy harvesting and energy transfer applications, along with electrochemical probes [1-8]. The key to these applications will be the development of

Address correspondence to igor.medintz@nrl.navy.mil 
facile methods that allow the QDs, and indeed a variety of other nanoparticles, to be conjugated to all types of biomolecules (i.e., proteins, peptides, DNA, etc.) as desired, with stability and control over valence [9]. We have previously demonstrated that metal-affinity coordination can drive the rapid selfassembly of various polyhistidine-appended proteins and peptides onto the metal-rich surface of QDs [10 -13]. This conjugation strategy is highly stable (low nanomolar binding constants), rapid and facile to implement, and is steadily being adopted by other research groups [10, 14-16].

Building on our understanding of polyhistidine coordination to the ZnS surface of QDs, we were able to extend the applicability of this strategy by synthesizing a reactive polyhistidine peptidyl linker that could be conjugated to modified DNA for subsequent self-assembly with QDs [17]. The linker consisted of a hexahistidine $\left(\mathrm{His}_{6}\right)$ sequence followed by a cysteine residue that was modified with a pyridyldisulfide on its thiol group. The linker was conjugated to thiolated DNA by disulfide exchange and the versatility of this approach demonstrated by self-assembling a fluorescence resonance energy transfer (FRET)-based QD-DNA molecular beacon that was able to sense the presence of its cognate DNA complement. The liability of this approach is the disulfide bond itself as it is susceptible to both reduction and back-exchange with other free thiols. This precludes its use in reducing environments such as the cellular cytoplasm or conjointly in formats that include gold nanoparticles. Here, we report an improved chemistry for conjugation of peptidyl linkers to similar thiol-modified DNA. The $\mathrm{His}_{6}$ functionality is retained unperturbed; however, the disulfide motif is replaced with a thiolreactive iodoacetyl group leading to a more robust nonhydrolyzable peptide-DNA linker that still allows the same facile self-assembly approach for bioconjugation to QDs, as shown schematically in Fig. 1. The synthesis, conjugation to modified DNA, self-assembly with QDs and characterization of the QD conjugates are described.

\section{Experimental}

\subsection{Materials}

Rink amide AM resin (200-400 mesh), 9-fluorenylmethoxycarbonyl (Fmoc)-His(trityl (Trt))$\mathrm{OH}$ and benzotriazole-1-yl-oxy-tris-pyrrolidinophosphonium hexafluorophosphate (PyBOP) were obtained from Novabiochem (Darmstadt, Germany). Diisopropylethylamine (DIPEA), piperidine, iodoacetic acid, and $\mathrm{N}$-hydroxysuccinimide were obtained from Aldrich (St. Louis, Missouri). Dichloromethane (DCM), dimethylformamide (DMF), triisopropylsilane (TIS), trifluoroacetic acid (TFA), and diisopropylcarbodiimide were obtained from Fluka (Buchs, Switzerland). The reagents for performing the Kaiser test were a generous gift from Dr. Claudio Paolucci of the Organic Chemistry Department "A. Mangini" at the University of Bologna. HPLC analysis and purification were performed on an Agilent 1100 system equipped with a PDA detector and employing a Zorbax SB-300, $300 \AA, 250 \mathrm{~mm} \times 9.4$ mm C18 reverse phase column (Agilent Technologies, Palo Alto, CA). Elution of peptides was monitored at $220 \mathrm{~nm}$. HPLC grade acetonitrile $(\mathrm{MeCN})$ was obtained from Aldrich, while $\mathrm{dd}_{2} \mathrm{O}(18.2 \mathrm{M} \Omega \cdot \mathrm{cm})$ was obtained from a Millipore Simplicity 185 system (Billerica, Massachusetts). The eluents were filtered through a $0.45 \mu \mathrm{m}$ nylon membrane prior

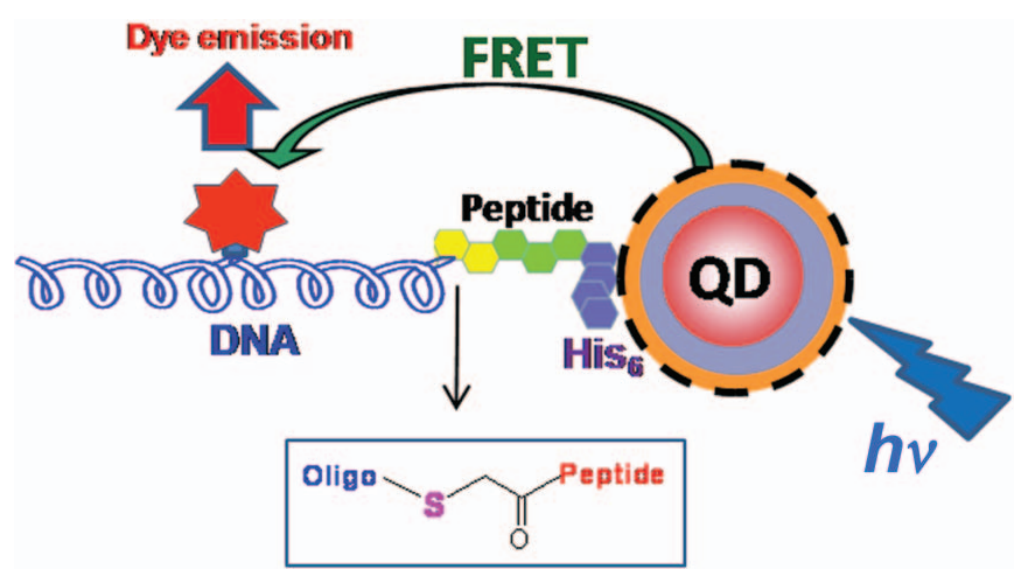

Figure 1 Schematic of the peptidyl-DNA conjugate as attached to a QD formed by the covalent linkage of the thiolated-DNA to the reactive iodoacetyl peptide which yields a thioether bond. Self-assembly of the peptidyl-DNA conjugate to the QD surface is mediated by the peptide terminal hexahistidine $\left(\mathrm{His}_{6}\right)$ sequence through metal-affinity coordination and results in efficient FRET from the QD donor to the dye attached on the proximal DNA 
to use. For the purification of the iodoacetamidederivatized peptides, the following HPLC gradient was employed at $t=0 \mathrm{~min}, B=0 ; t=30 \mathrm{~min}, B=15 \%$; flow $=2.5 \mathrm{~mL} / \mathrm{min}$, where $A=\mathrm{ddH}_{2} \mathrm{O}+0.1 \%$ TFA, and $B=\mathrm{MeCN}+0.1 \%$ TFA.

\subsection{Quantum dots}

CdSe/ZnS core/shell QDs with emission maxima centered at $\sim 520 \mathrm{~nm}$ and $530 \mathrm{~nm}$ were synthesized as previously described, using a stepwise reaction of organometallic precursors in a hot coordinating solvent mixture [18]. The QDs were made hydrophilic by exchanging the native organic capping shell with dihydrolipoic acid (DHLA) ligands as described elsewhere [18], and the quantum yield was determined to be $\sim 20 \%$. QD absorption/emission spectra can be found in Fig. 4(a).

\subsection{Synthesis of succinimidyl ester- iodoace-tamide}

The succinimidyl ester(OSu) of iodoacetic acid (3) in Scheme 1, Fig. 2 was prepared by mixing iodoacetic acid $(1.86 \mathrm{~g}, 10 \mathrm{mmol})$ with $\mathrm{N}$-hydroxysuccinimide $(1.15 \mathrm{~g}, 10$ $\mathrm{mmol}$ ) in anhydrous ethyl acetate (50 $\mathrm{mL}$ ). Diisopropylcarbodiimide (1.55 $\mathrm{mL}, 10 \mathrm{mmol}$ ) was slowly added and the mixture reacted for $4 \mathrm{~h}$ at room temperature. The precipitated urea by-product was removed by filtration and the resulting clear solution was first concentrated and then crystallized from anhydrous isopropyl alcohol to obtain $(2.47 \mathrm{~g}$, $8.7 \mathrm{mmol}$, $87 \%$ ) of a white crystalline solid (m.p. $\left.144-148{ }^{\circ} \mathrm{C}\right)$.

\subsection{Synthesis of (His) ${ }_{6}-\mathrm{NH}_{2}$}

The hexahistidine backbone was synthesized as described in Ref. [17], see Scheme 1 (Fig. 2). Briefly, Rink amide was pre-swelled in DCM for $2 \mathrm{~h}$ in a disposable polyethylene cartridge

(5)
(Supelco, Bellefonte, Pennsylvania) equipped with a polyethylene frit and thoroughly rinsed with DCM $(3 \times)$ and with DMF $(3 \times)$. For Fmoc deprotection, piperidine (20\% in DMF) was added to the resin and reacted for $1 \mathrm{~h}$. The resin was washed with DMF (3x), DCM $(3 \times)$ and methanol ( $3 \times)$. Removal of the Fmoc protective group was confirmed by a positive Kaiser test. If the Kaiser test did not give a satisfactory result, deprotection and washing were repeated. For residue coupling, the resin was rinsed with DCM (5x). Fmoc-protected histidine (2.5 eq.), PyBOP (2.5 eq.),

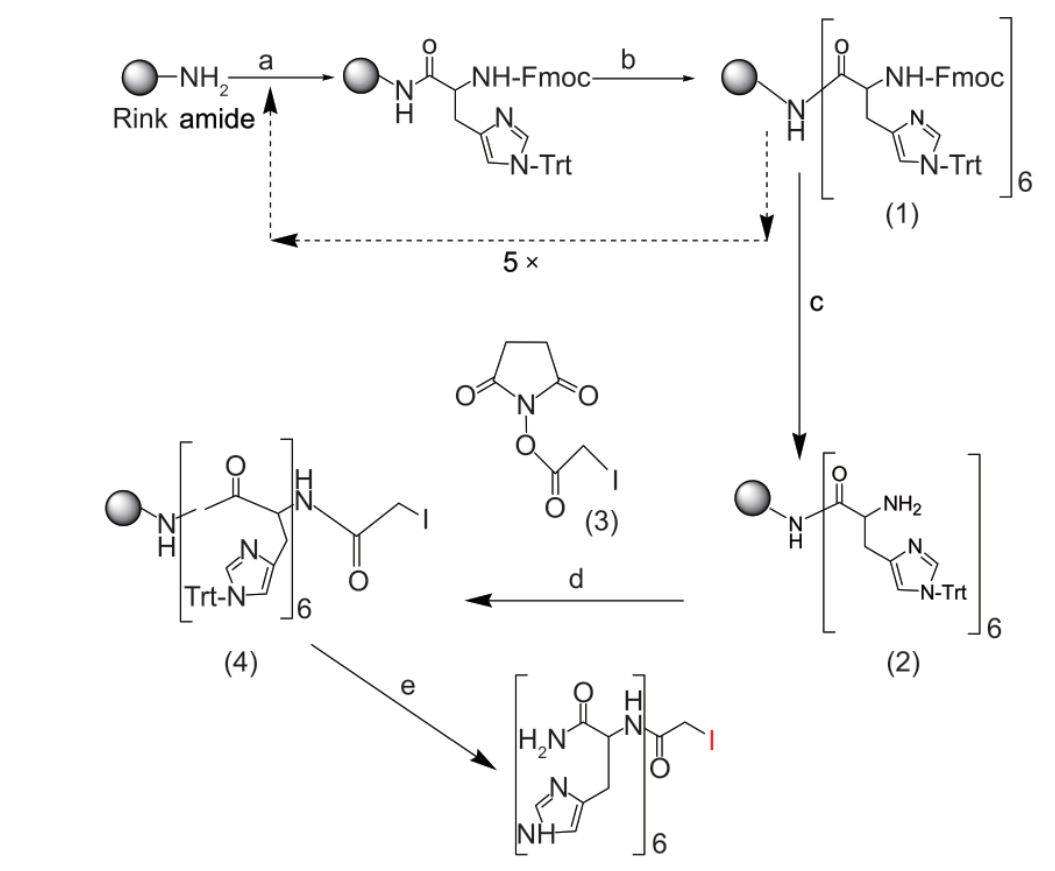

(5)

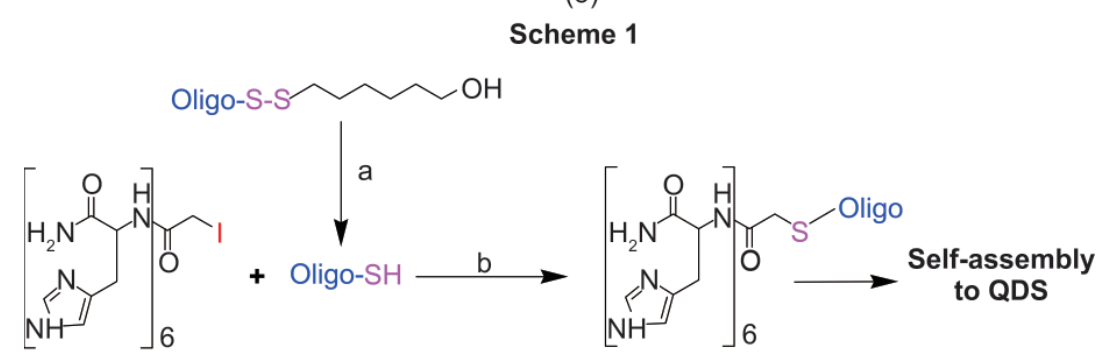

(6)

Scheme 2

Figure 2 Scheme 1. Synthesis of the thiol-reactive iodoacetyl $\mathrm{His}_{6}$ peptidyl linker. Histidine residue coupling: (a, b) Fmoc-(Trt)-His-OH 2.5 eq., PyBOP 2.5 eq., DIPEA 5 eq., in DCM for $2 \mathrm{~h}$ and repeated 6 times. Fmoc deprotection of the primary amine: (c) $20 \%$ piperidine in DMF, $0.5 \mathrm{~h}$. Modification of the primary amine with OSu-iodoacetate: (d) $>10$ eq. of OSu-iodoacetate in DCM, $2 \mathrm{~h}$. Cleavage from the resin/Trityl deprotection: TFA : TIS: $\mathrm{H}_{2} \mathrm{O}(95: 2.5: 2.5), 3 \mathrm{~h}$. Scheme 2. Generation of a His ${ }_{6}$-appended oligopeptide. Reduction of thiol-protected oligonucleotide: (a) DTT- $\mathrm{KH}_{2} \mathrm{PO}_{4}$ buffer $\mathrm{pH}$ 8; thiol conjugation (b) $\mathrm{KH}_{2} \mathrm{PO}_{4}$-EDTA buffer $\mathrm{pH}$ 8. See Experimental section for the meaning of abbreviations of chemical reagents and synthetic details 
and DIPEA (5 eq.) were added directly to the resin in the cartridge with the minimum amount of DCM required to ensure solubilization of the reactants and the mixture reacted for $2 \mathrm{~h}$ while shaking. After coupling, the resin was rinsed with DCM $(3 \times)$ and methanol $(3 \times)$. The outcome of the reaction was monitored by Kaiser test and the coupling and washing steps were repeated if needed. Coupling and deprotection were repeated until the sequence Rink(His) ${ }_{6}$-NH-Fmoc (compound (1)) was obtained. After the attachment of the terminal His residue, the Fmoc protective group was removed as usual and the resin washed as before to yield the free terminal primary amine.

\subsection{OSu-iodoacetate coupling to Rink-(His) ${ }_{6}-\mathrm{NH}_{2}$}

An excess (>10 eq.) of OSu-iodoacetate (3) was dissolved in $100 \mu \mathrm{L}$ of dry DCM and added to $50 \mathrm{mg}$ of the resin-bound peptide, and the mixture shaken for $2 \mathrm{~h}$. The resin was then washed with DMF (3x), $\operatorname{DCM}(3 \times)$ and finally with methanol $(3 \times)$ to yield Compound (4).

\subsection{Peptide cleavage}

Cleavage from the resin and trityl group deprotection was achieved by treatment with TFA:TIS : $\mathrm{H}_{2} \mathrm{O}$ (95:

$2.5: 2.5)$ for $3 \mathrm{~h}$. The solution was filtered through the cartridge frit and collected in Eppendorf tubes. The resin was then rinsed twice with TFA. The fractions collected were concentrated under reduced pressure until only a small volume was left. Cold $\left(-20^{\circ} \mathrm{C}\right)$ diethyl ether (5 volumes) was then added to precipitate the crude peptide which was centrifuged and the supernatant removed. The pellet obtained was rinsed with cold diethyl ether and resuspended in $1: 1 \mathrm{MeCN}: \mathrm{ddH}_{2} \mathrm{O}+0.1 \%$ TFA. The crude peptide was purified by HPLC to yield the $\mathrm{His}_{6}$-iodoacetamide derivative-Compound (5). Mass spectral analysis confirmed the synthesis (ESI-MS: $\left.1008.26\left[\mathrm{M}^{+}\right], 504.65\left[\mathrm{M}^{2+}\right]\right)$.

\subsection{Conjugation of Compound (5) to thiolated-DNA}

A synthetic oligonucleotide with the sequence 5'- [ThiSS] [TAMdT]-GAGCTCGTTCGTCTGAAGGTGAATGGCAG-3' (where ThiSS is a thiol modifier with a six-carbon spacer, and TAMdT is a DNA T-base modified with tetramethyl-6-carboxyrhodamine/ TAMRA on a sixcarbon spacer, with length $30 \mathrm{bp}, M_{\mathrm{w}} 10385$, and $T_{\mathrm{m}}$ $69.9^{\circ} \mathrm{C}$ ) was obtained from Operon Biotechnologies (Huntsville, Alabama). The oligonucleotide was deprotected by reduction with $0.04 \mathrm{~mol} / \mathrm{L}$ dithiothreitol (DTT) in $100 \mathrm{mmol} / \mathrm{L} \mathrm{KH}_{2} \mathrm{PO}_{4}$ buffer $\mathrm{pH} 8$ at $37{ }^{\circ} \mathrm{C}$ overnight and purified using two consecutive PD-10 gel permeation columns (GE Healthcare, Piscataway, New Jersey). A two to three fold excess of Compound (5) was immediately added to the freshly deprotected oligonucleotide and reacted for $2 \mathrm{~h}$ in $\mathrm{KH}_{2} \mathrm{PO}_{4}$ buffer. The reaction was carried out at slightly alkaline $\mathrm{pH}$ where thiolmodification by the iodoacetyl is the exclusive reaction, thus negating non-specific reactivity towards amines or other groups [19]. At the end of the reaction the peptide-appended DNA was purified by PD-10 gel chromatography, estimated quantitatively using the extinction coefficient of both the DNA and TAMRA dye, dried under vacuum and stored at $-20^{\circ} \mathrm{C}$ until use.

\subsection{Self-assembly of $\mathrm{His}_{6}$-peptide modified DNA with QDs}

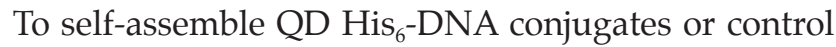
samples at the desired valence, His-appended DNA at the appropriate molar ratios was added to 0.25 $\mu \mathrm{mol} / \mathrm{L}$ of DHLA-capped QDs emitting at $520 \mathrm{~nm}$ in $10 \mathrm{mmol} / \mathrm{L}$ sodium tetraborate buffer $\mathrm{pH} 8(100 \mu \mathrm{L}$ in total) and allowed to incubate at room temperature for $\sim 30 \mathrm{~min}$. Samples for agarose gel analysis were prepared in the same manner but using lower concentrations and smaller volumes.

\subsection{Fluorescence resonance energy transfer analysis}

Fluorescence spectra from the QD-peptidyl conjugates were collected on a Tecan Safire Dual Monochromator Multifunction Microtiter Plate Reader (Tecan, Research Triangle Park, NC) using 300 $n m$ excitation. FRET efficiency $E$ was calculated from each sample set using the expression:

$$
E=\frac{\left(F_{\mathrm{D}}-F_{\mathrm{DA}}\right)}{F_{\mathrm{D}}}
$$

where $F_{\mathrm{D}}$ and $F_{\mathrm{DA}}$ are the deconvoluted fluorescence intensities of the donor alone and the donor in the 
presence of acceptor(s), respectively [20]. QD-donor dye-acceptor separation distances $r$ were estimated by fitting the FRET efficiencies $E$ using Förster theory and the distribution of the number of acceptors per QD [21-23]. The quenching efficiency from a QD donor conjugated to exactly $n$ acceptors is given by:

$$
E(n)=\frac{n}{n+\left(r / R_{0}\right)^{6}}
$$

Equation (2) is specific to a centrosymmetric QD donor-fluorophore acceptor conjugate where $r$ is the center-to-center donor-acceptor distance and $R_{0}$ is the Förster distance corresponding to the donoracceptor separation that results in 50\% energy efficiency [20, 22]. The FRET analysis also accounted for the contribution and any deviation due to Poisson distribution effects on low valence during the selfassembly process as described in Ref. [13, 21, 23].

\section{Results and discussion}

The schemes in Fig. 2 illustrate the synthetic pathway utilized for generating both the iodoacetyl reactive peptide linker and its subsequent conjugation to thiolated-DNA. The core $\mathrm{His}_{6}$ sequence was obtained by standard solid phase peptide synthesis (SPPS) and a single terminal primary amine on the Rink solid phase-attached peptide was made available by deprotecting the Fmoc group. This amine was subsequently modified with the OSu-iodoacetate (3) and the peptide cleaved from the solid phase along with deprotection of the imidazole trityl-group by acid treatment to yield the final thiol-reactive peptide (5). Successful modification of the $\mathrm{His}_{6}$ sequence with Compound (3) and its stability during the subsequent acid-cleavage/deprotection procedure demonstrates the robustness of this particular group. Further, the small size of the $\mathrm{His}_{6}$ sequence translates into the ability to generate relatively large amounts/ yields by SPPS as opposed to the lower yields that very often result when synthesizing and purifying longer peptide lengths. As with the previous version, the reactive peptidyl-linker could be stored dry for long periods of time until needed and also shipped over long distances. Indeed, samples of reactive linker were stored for more than one year and still remained viable.

To demonstrate the general applicability of this improved peptide design, we obtained a TAMRA dye-labeled DNA oligonucleotide with a 5' protectedthiol group, very similar in sequence to that utilized previously [17]. Using standard procedures, the thiol group on the oligonucleotide was deprotected by reduction with DTT, reacted with a slight molar excess of the iodoacetyl-modified peptide (5) and the resulting peptidyl-DNA conjugate (6) purified using simple gravity-flow gel permeation chromatography on a disposable column as described above. Selfassembly of the peptide-DNA with the QDs was performed at room temperature in microcentrifuge tubes and peptide-DNA valence controlled through the molar ratio added relative to QD. The selfassembly was first confirmed using agarose gelelectrophoresis, see Fig. 3. $530 \mathrm{~nm}$ QDs were selfassembled with both the $\mathrm{His}_{6}$ TAM DNA construct

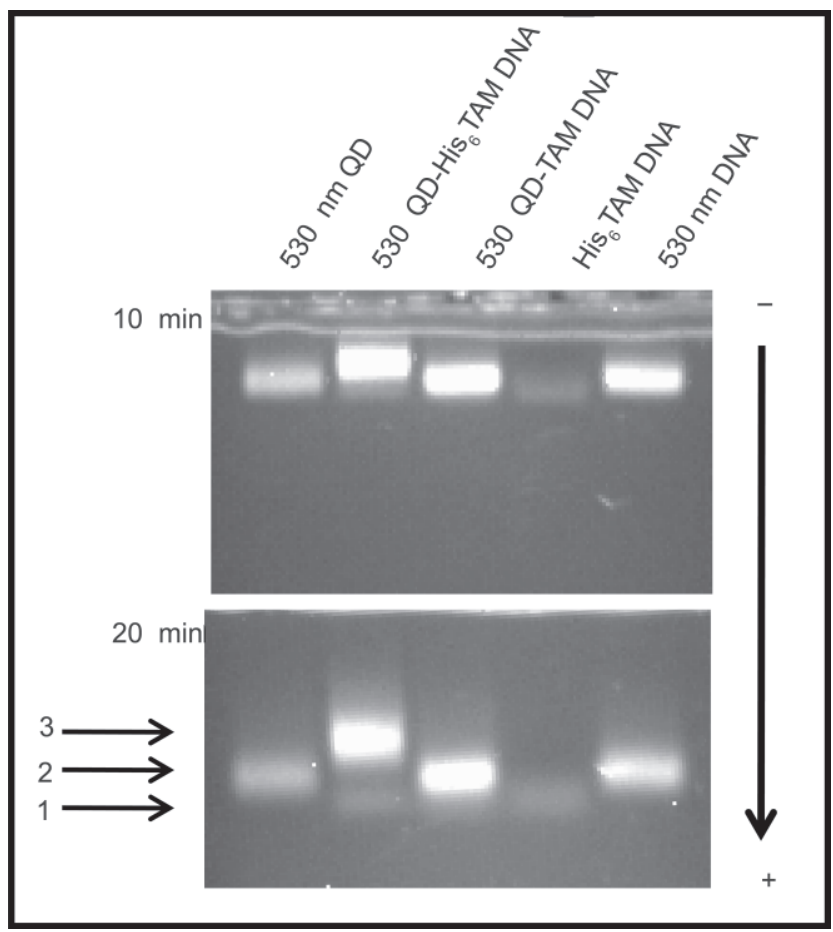

Figure 3 Agarose gel electrophoresis of $530 \mathrm{~nm}$ QDs selfassembled with tetramethyl-6-carboxyrhodamine (TAMRA) dyelabeled DNA, valence of >30 DNA / QD. 10 pmol of $530 \mathrm{~nm}$ DHLAfunctionalized QDs were self-assembled with either $\mathrm{His}_{6}$-linker modified TAM DNA ( His $_{6}$ TAM DNA) or unmodified TAM DNA and separated in $2 \%$ agarose gels supplemented with 1 X TBE $(0.089$ $\mathrm{mol} / \mathrm{L}$ Tris, $0.089 \mathrm{~mol} / \mathrm{L}$ borate, $0.002 \mathrm{~mol} / \mathrm{L}$ EDTA pH 8.3) in $1 \mathrm{X}$ TBE running buffer. The three resolved species indicated are: (1) His 6 TAM DNA, (2) 530 nm QDs, and (3) 530 nm QD-His ${ }_{6}$ TAM DNA conjugates 
(6) and unmodified TAM DNA control and then separated in a $2 \%$ agarose gel. As can be seen in the two images in Fig. 3, three distinct species are visible and become better resolved with longer separation times due to their differential mobility. Species 1 corresponds to the unmodified TAM DNA oligonucleotide and this has the highest relative migration rate, Species 2 is the $530 \mathrm{~nm}$ QDs where the strong negative charge of the DHLA ligand carboxy group promotes electrophoretic migration, and Species 3 is the QD-His ${ }_{6}$ TAM DNA conjugate. The lower quantum yield and non-optimal excitation makes the TAMRA fluorescence rather weak relative to that of the QDs. However, the assembly of $\mathrm{His}_{6}$ TAM DNA with the QDs results in brighter overall band fluorescence due to some FRET contributions (see below). The addition of multiple selfassembled DNA moieties to the QDs results, in this case, in retardation of the migration rate making the QD-His ${ }_{6}$ TAM DNA conjugate the slowest moving species. The large molar excess of $\mathrm{His}_{6}$ TAM DNA used during self-assembly also results in some unconjugated DNA present along with the QD-conjugates and this can also be seen in the gels. These results confirm that modification of the DNA with the thiol-reactive $\mathrm{His}_{6}$ peptide promotes direct self-assembly on the QD surface. In the absence of the peptide, the mutual negative charges, and thus the repulsion of the DHLA QDs and the DNA, serve to prevent both assembly and non-specific interactions.

Having verified self-assembly of QD$\mathrm{His}_{6}$ TAM DNA, we proceeded to analyze the FRET interactions between $520 \mathrm{~nm}$ emitting QDs and the TAMRA dye on the proximal selfassembled DNA. Figure 4(a) shows the excellent spectral overlap of the $520 \mathrm{~nm}$ QD donorTAMRA dye acceptor pair utilized in these experiments. These give rise to a calculated Föster distance or $R_{0}$ value of $62 \AA$. We monitored the FRET efficiency of the QD donor as an increasing ratio of $\mathrm{His}_{6}$ TAM DNA was selfassembled onto the central nanocrystals. Figure

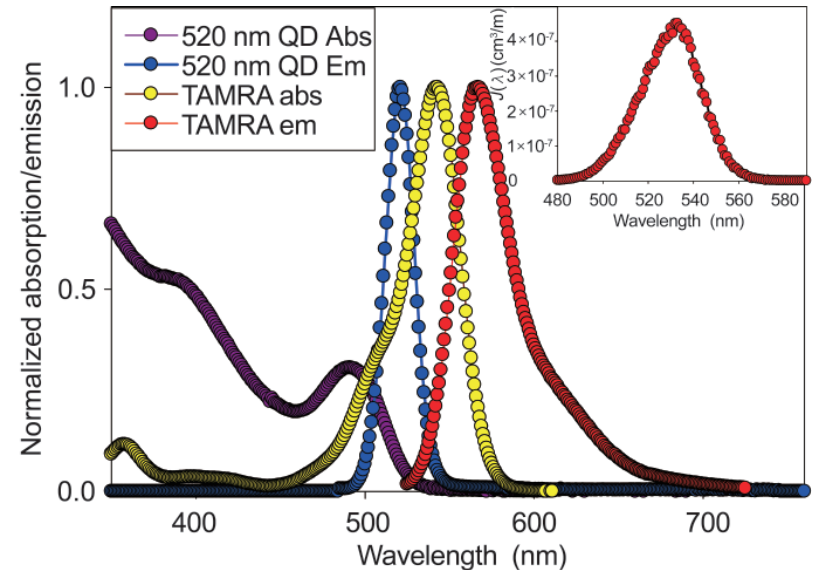

(a)

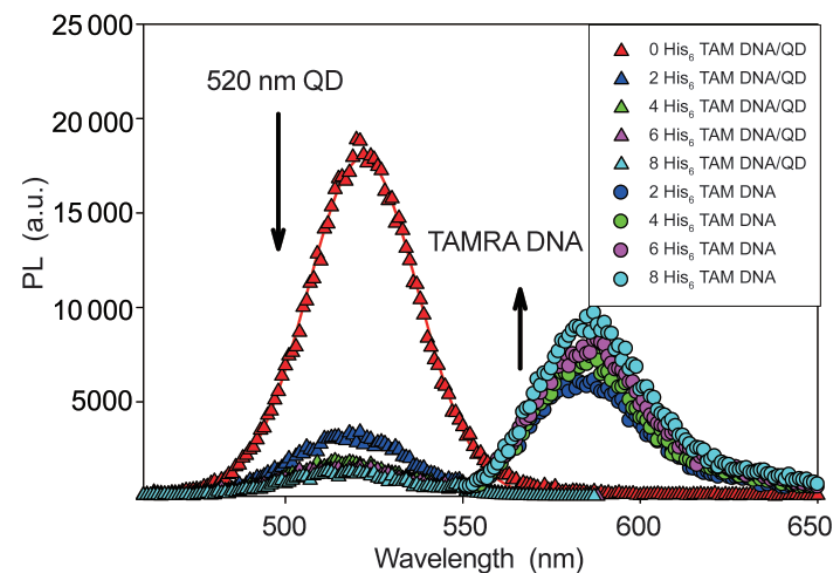

(b)

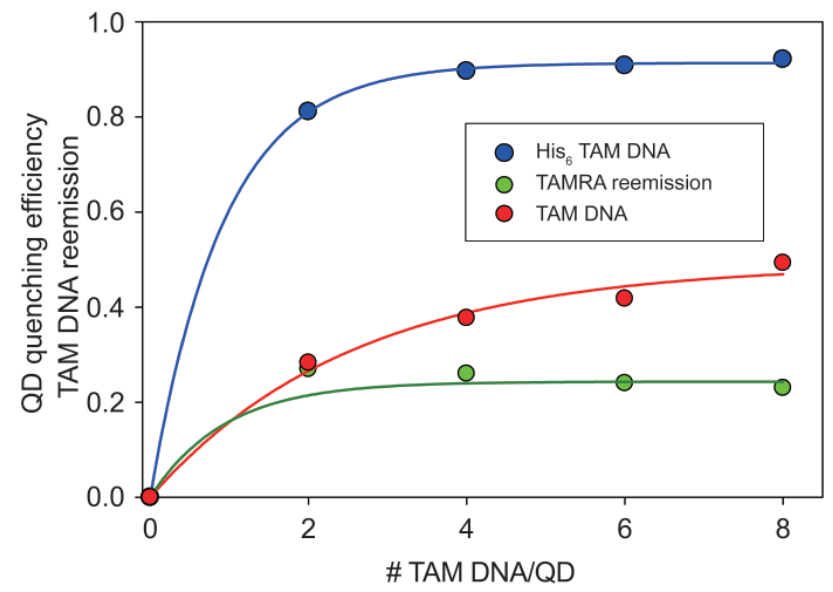

(c)

Figure 4 FRET analysis. (a) Absorption and emission of $520 \mathrm{~nm}$ QDs and tetramethyl-6-carboxyrhodamine (TAMRA) dye. QD quantum yield (QY) is $\sim 20 \%$. TAMRA properties: $\lambda_{\text {abs. max }} 555 \mathrm{~nm} / \lambda_{\text {em. max }} 580 \mathrm{~nm}$, extinction coefficient $\sim 91000(\mathrm{~mol} / \mathrm{L})^{-1} \cdot \mathrm{cm}^{-1}$, QY $\sim 23 \%$ [29]. The inset shows the QD-TAMRA spectral overlap. (b) Representative deconvoluted spectra collected from $520 \mathrm{~nm}$ QDs self-assembled with increasing ratios of $\mathrm{His}_{6}$ TAM DNA conjugates. The QD spectra were fitted with a Gaussian profile. QD quenching and TAMRA reemission are indicated. (c) Plot of $520 \mathrm{~nm}$ QD quenching efficiency vs TAMRA ratio after self assembly with $\mathrm{His}_{6}$ TAM DNA conjugates along with TAMRA re-emission and QD quenching after exposure to unmodified TAM DNA controls 
4(b) shows representative spectra (deconvoluted and corrected for the direct acceptor excitation contribution) collected as the acceptor valence was increased incrementally in steps, while Fig. 3(c) shows the corresponding QD quenching efficiency along with TAMRA re-emission derived from the same QD-His ${ }_{6}$ TAM DNA conjugates. QD quenching observed at the same valences in the presence of unmodified TAM DNA controls is also included in this figure. At just a nominal ratio of 2 DNA acceptors, the QD donor PL was quenched slightly more than $80 \%$ and quenching then effectively reached a plateau at $\sim 90 \%$ for $>4$ acceptors/QD. The TAMRA re-emission remained unperturbed after reaching around $20 \%$ at a ratio of 2 , where it continued to linearly track the QD quenching. As with previous studies where we used TAMRA as an acceptor dye, we note that TAMRA is an effective quencher of QDs. The modest rate of TAMRA-sensitized re-emission can be attributed to a combination of the intrinsic properties of this dye along with contributions from inner-filtering and self-quenching at higher valence. In contrast, exposing the same QDs to unmodified TAM DNA results in substantially less quenching and this result can be ascribed to solution-phase FRET interactions [20].

Analysis of the QD-TAMRA FRET data gives a corrected average QD center-to-dye center $r$ value of $49 \AA$ which is in reasonable agreement with the previous conjugates, where an average separation distance of $\sim 40 \AA$ was obtained [17]; the differences can be accounted for by the smaller QDs used in the previous study along with differences in peptide structure and DNA sequence. The $530 \mathrm{~nm}$ QD hard radius is estimated to be in the range of $\sim 28-30 \AA$ [24] and the $\mathrm{His}_{6}$ portion of the peptide is assumed to be directly attached to the QD surface by a minimum of at least 4 histidines [10], and thus it will only contribute to the overall lateral extension by $<5 \AA$. The combination of the remaining 6-carbon linker that joins the thiol group to the DNA, along with the modified T-nucleotide and the extended diamino/6carbon spacer linking the TAMRA dye to this T-base more than account for the remaining 14-15 $\AA$ of lateral peptide-DNA length even when not fully extended (energy minimized) or when accounting for some heterogeneity in conformation. Similar results were obtained when self-assembling the same peptide-DNA conjugates with polyethylene glycol (PEG)-modified QDs (data not shown) [25, 26].

\section{Conclusions}

Peptide-DNA conjugates are relatively well described in the literatures and have been extensively applied for nucleic acid, gene, and molecular beacon delivery to cells [27]. This has led to the development of several different covalent and noncovalent methods to accomplish the linkage or association of these two species. Disulfide bonds have been purposely introduced as the linking group between the peptide and the oligonucleotide in these hybrid species as intracellular reduction of the conjugate can facilitate the intracellular separation of both species. For example, Nitin and co-workers tested both reducible and non-reducible linkers when linking molecular beacons to cell delivery peptides for the purpose of monitoring mRNA expression in living cells [28]. In our case, apart from some specific intracellular delivery applications, reduction of the disulfide linkage on a QD-DNA conjugate could be a liability in both in vivo and in vitro experiments as it would dissociate the QD-attached biomolecule or probe. We thus focused here on developing a modified chemistry that provides almost all the benefits of this polyhistidine-driven QD self-assembly bioconjugation approach but removed the reducible disulfide linkage. Use of a reactive iodoacetylgroup allowed targeting of the same thiols while shortening the peptide linker as compared to the previous by one residue in length. Discussion of the reducibility of disulfide bonds and the strength and long-term stability of iodoacetyl functional groups and thioether bonds can be found in the Refs. [19, 29]. It is worth noting that identical $\mathrm{His}_{6}$ sequences can be purchased commercially from vendors along with the OSu-iodoacetamide (3). Such commercially obtained $\mathrm{His}_{6}$-sequences would only contain one primary amine allowing it to be easily modified with the iodoacetamide to provide the same functional reactive linker. As thiol groups occur 
naturally in many proteins including antibodies, can be engineered into cloned proteins recombinantly, inserted into nascent peptides or added to DNA during synthesis, the chemistry demonstrated here can provide a simple method for self-assembling a variety of stable QD bioconjugates. Although a noncovalent conjugation strategy is used here, the ratio of $\mathrm{His}_{6}$ peptide and thus acceptor DNA acceptor per QD is also easily controlled through the molar ratio added for self-assembly with the QD as repeatedly demonstrated in Refs. $[1,2,6,7,11,13$, $14,21,23]$ and discussed in detail in references [13, 21, 23].

The ability to switch the functional reactive group on the $\mathrm{His}_{6}$ peptide to those that target amines, for example, succinimidyl esters or isothiocyanates, or alternatively periodate groups that target the sugar residues on carbohydrates can allow for multiple types of biomolecules to be targeted for self-assembly with the QDs [29]. Further, combining these types of linkers in one experiment can allow different orthogonally-targeted biomolecules to be self-assembled with the same QD to create multifunctional probes. Alternatively, switching the peptide sequences to those that recognize other metals or semiconductors can potentially allow selfassembly of similar biomolecules with a variety of other nanoparticle surfaces [30]. Lastly, it is also worth mentioning that several recent studies have suggested that it is possible to self-assemble polyhistidine modified proteins and peptides with commercial QD preparations [31, 32]. This can extend the choice to many different QD-biomolecule pairs and allow greater flexibility in incorporating them into more complex functional probes and nanostructures [9].

\section{Acknowledgements}

The authors acknowledge Stephen Lee and Ilya Elashvilli of the CB Directorate/Physical S\&T Division (DTRA), ONR, NRL, and the NRLNSI for financial support. K.B. acknowledges an ASEE fellowship through NRL. The authors also gratefully acknowledge Dr. Hedi Mattoussi, NRL, for providing the luminescent quantum dots utilized in this study.

\section{References}

[1] Daniel, M. C.; Astruc, D. Gold nanoparticles: Assembly, supramolecular chemistry, quantum-size-related properties, and applications toward biology, catalysis, and nanotechnology. Chem. Rev. 2004, 104, 293-346.

[2] Medintz, I.; Uyeda, H.; Goldman, E.; Mattoussi, H., Quantum dot bioconjugates for imaging, labelling and sensing. Nat. Mater. 2005, 4, 435-446.

[3] Michalet, X.; Pinaud, F. F.; Bentolila, L. A.; Tsay, J. M.; Doose, S.; Li, J. J.; Sundaresan, G.; Wu, A. M.; Gambhir, S. S.; Weiss, S. Quantum dots for live cells, in vivo imaging, and diagnostics. Science 2005, 307, 538-544.

[4] Alivisatos, P. The use of nanocrystals in biological detection. Nat. Biotechnol. 2004, 22, 47-52.

[5] Clapp, A. R.; Medintz, I. L.; Mattoussi, H. Forster resonance energy transfer investigations using quantumdot fluorophores. ChemPhysChem 2005, 7, 47-57.

[6] Sapsford, K. E.; Pons, T.; Medintz, I. L.; Mattoussi, H. Biosensing with luminescent semiconductor quantum dots. Sensors 2006, 6, 925-953.

[7] Sapsford, K. E.; Bradburne, C.; Detehanty, J. B.; Medintz, I. L. Sensors for detecting biological agents. Mater. Today 2008, 11, 38-49.

[8] Sapsford, K. E.; Berti, L.; Medintz, I. L. Materials for fluorescence resonance energy transfer analysis: Beyond traditional donor-acceptor combinations. Angew. Chem. Int. Ed. 2006, 45, 4562-4588.

[9] Medintz, I. Universal tools for biomolecular attachment to surfaces. Nat. Mater. 2006, 5, 842.

[10] Sapsford, K. E.; Pons, T.; Medintz, I. L.; Higashiya, S.; Brunel, F. M.; Dawson, P. E.; Mattoussi, H. Kinetics of metal-affinity driven self-assembly between proteins or peptides and CdSe-ZnS quantum dots. J. Phys. Chem. C 2007, 111, 11528-11538.

[11] Medintz, I. L.; Clapp, A. R.; Mattoussi, H.; Goldman, E. R.; Fisher, B.; Mauro, J. M. Self-assembled nanoscale biosensors based on quantum dot FRET donors. Nat. Mater. 2003, 2, 630-638.

[12] Delehanty, J. B.; Medintz, I. L.; Pons, T.; Brunel, F. M.; Dawson, P. E.; Mattoussi, H. Self-assembled quantum dot-peptide bioconjugates for selective intracellular delivery. Bioconj. Chem. 2006, 17, 920-927.

[13] Medintz, I. L.; Clapp, A. R.; Brunel, F. M.; Tiefenbrunn, T.; Uyeda, H. T.; Chang, E. L.; Deschamps, J. R.; Dawson, P. E.; Mattoussi, H. Proteolytic activity monitored 
by fluorescence resonance energy transfer through quantum-dot-peptide conjugates. Nat. Mater. 2006, 5, 581-589.

[14] Goldman, E.; Medintz, I.; Whitley, J.; Hayhurst, A.; Clapp, A.; Uyeda, H.; Deschamps, J.; Lassman, M.; Mattoussi, H. A hybrid quantum dot-antibody fragment fluorescence resonance energy transfer-based TNT sensor. J. Am. Chem. Soc. 2005, 127, 6744-6751.

[15] Ipe, B. I.; Niemeyer, C. M. Nanohybrids composed of quantum dots and cytochrome P450 as photocatalysts, Angew. Chem. Int. Ed. 2006, 45, 504-507.

[16] Liu, W.; Howarth, M.; Greytak, A. B.; Zheng, Y.; Nocera, D. G.; Ting, A. Y.; Bawendi, M. G. Compact biocompatible quantum dots functionalized for cellular imaging. J. Am. Chem. Soc. 2008, 130, 1274-1284.

[17] Medintz, I. L.; Berti, L.; Pons, T.; Grimes, A. F.; English, D. S.; Alessandrini, A.; Facci, P.; H., M. A reactive peptidic linker for self-assembling hybrid quantum dot-DNA bioconjugates. Nano Lett. 2007, 7, 1741-1748.

[18] Mattoussi, H.; Mauro, J. M.; Goldman, E. R.; Anderson, G. P.; Sundar, V. C.; Mikulec, F. V.; Bawendi, M. G. Selfassembly of CdSe-ZnS quantum dot bioconjugates using an engineered recombinant protein, J. Am. Chem. Soc.

2000, 122, 12142-12150.

[19] Hermanson, G. T. Bioconjugate Techniques; Academic Press: San Diego, 2008.

[20] Lakowicz, J. R. Principles of Fluorescence Spectroscopy; Springer: New York, 2006.

[21] Pons, T.; Medintz, I. L.; Wang, X.; English, D. S.; Mattoussi, H. Solution-phase single quantum dot fluorescence resonance energy transfer. J. Am. Chem. Soc. 2006, 128, 15324-15331.

[22] Clapp, A. R.; Medintz, I. L.; Mauro, J. M.; Fisher, B. R.; Bawendi, M. G.; Mattoussi, H. Fluorescence resonance energy transfer between quantum dot donors and dyelabeled protein acceptors. J. Am. Chem. Soc. 2004, 126, 301-310.

[23] Pons, T.; Uyeda, H. T.; Medintz, I. L.; Mattoussi, H.
Hydrodynamic dimensions, electrophoretic mobility, and stability of hydrophilic quantum dots. J. Phys. Chem. B. 2006, 110, 20308-20316.

[24] Dabbousi, B. O.; Rodriguez-Viejo, J.; Mikulec, F. V.; Heine, J. R.; Mattoussi, H.; Ober, R.; Jensen, K. F.; Bawendi, M. G. (CdSe)ZnS core-shell quantum dots: Synthesis and characterization of a size series of highly luminescent nanocrystallites. J. Phys. Chem. B. 1997, 101, 94639475.

[25] Uyeda, H. T.; Medintz, I. L.; Jaiswal, J. K.; Simon, S. M.; Mattoussi, $H$. Synthesis of compact multidentate ligands to prepare stable hydrophilic quantum dot fluorophores. J. Am. Chem. Soc. 2005, 127, 3870-3878.

[26] Susumu, K.; Uyeda, H. T.; Medintz, I. L.; Pons, T.; Delehanty, J. B.; Mattoussi, H. Enhancing the stability and biological functionalities of quantum dots via compact multifunctional ligands. J. Am. Chem. Soc. 2007, 129, 13987-13996.

[27] Venkatesan, N.; Kim, B. H. Peptide conjugates of oligonucleotides: Synthesis and applications. Chem. Rev. 2006, 106, 3712-3761.

[28] Nitin, N.; Santangelo, P. J.; Kim, G.; Nie, S. M.; Bao, G. Dual FRET molecular beacons for mRNA detection in living cells. Nucl. Acids Res. 2004, 32, e57.

[29] Haugland, R. P. The Handbook: A Guide to Fluorescent Probes and Labeling Technologies; Invitrogen: San Diego, 2005.

[30] Sarikaya, M.; Tamerler, C.; Schwartz, D. T.; Baneyx, F. $O$. Materials assembly and formation using engineered polypeptides. Ann. Rev. Mat. Res. 2004, 34, 373-408.

[31] Dennis, A. M.; Bao, G. Quantum dot-fluorescent protein pairs as novel fluorescence resonance energy transfer probes. Nano Lett. 2008, 8, 1439-1445.

[32] Yao, H.; Zhang, Y.; Xiao, F.; Xia, Z.; Rao, J. Quantum dot/ bioluminescence resonance energy transfer based highly sensitive detection of proteases. Angew. Chem. Int. Ed. 2007, 46, 4346-4349. 